\title{
Seismic response of a stock of social housings in Italy with R.C. and masonry materials.
}

\author{
Elisa Bonannini ${ }^{1, a}$, Marco Cinotti ${ }^{1, b}$, Mario Lucio Puppio ${ }^{1, \mathrm{c}}$, Mauro Sassu $\mathrm{u}^{2, \mathrm{~d}^{*}}$ \\ ${ }^{1}$ Department of Energy, Systems, Territory and Construction Engineering - \\ University of Pisa, Largo Lucio Lazzarino n.1 - 56126 Pisa (Italy). \\ ${ }^{2}$ Department of Civil Engineering, Environment and Architecture - \\ University of Cagliari, Via Marengo n.2 - 09123 Cagliari (Italy). \\ aelisa.bonannini@virgilio.it, ${ }^{\mathrm{b}} \mathrm{ml}$. puppio@ing.unipi.it, ${ }^{\mathrm{c}} \mathrm{cinottimarco@libero.it}{ }^{\mathrm{d}} \mathrm{msassu@unica.it}$
}

Keywords: Seismic vulnerability, Masonry structure, R.C. structure, Irregularities, SAVE procedure.

\begin{abstract}
The paper is based on a survey activity on a subset of 48 buildings for social housings. The structural materials are R.C. and Masonry. They are representative of about 9000 social flats on the district of Leghorn (Italy), built from early '900 up to 1981, date of adoption of seismic norms. The subset is divided into 15 masonry structures and 33 r.c. frames. Two different methods are adopted to classify the stock from seismic point of view. The stock has been classified in terms of Iv (Vulnerability Index) through GNDT $2^{\circ}$ level forms and PGA (Peak Ground Acceleration) from operation and collapse limit states (SLO and SLC), calculated by SAVE procedure. An example of classification, to establish priorities for further seismic investigations, is furnished. Main recurrent vulnerable details are highlighted, together with perspectives for more detailed seismic analysis.
\end{abstract}

\section{Introduction.}

The investigation of seismic properties of large stock of public buildings, as public social housing s, requires specific strategies to determine quick and easy to use classification rules. In most cases wide stocks of similar constructions are featured by different ages, constructive properties and maintenance levels. Recent destructive earthquakes that affected Italian territory displayed that seismic deficiencies of buildings are associated to a wide number of structural aspects, together local geotechnical features $[1,2]$. On the other hand, the management of a large number of social houses requires specific strategies to choice the buildings in which to address the attention of structural analysis. Indeed is not possible to investigate all the constructions in the meaning time with the same level of detail. The seismic vulnerability of a construction involves different aspect and affect both structural and non structural components. It is well known that it can be quickly examined only through specific procedures, like Italian INGV or SAVE forms. The aim is to assess the maximum PGA (Peak Ground Acceleration) or "PGA capacity" compatible with the safety or the several structural performances. The geotechnical aspect can be associated to the "PGA demand" of the soil, throughout well known classifications into specific categories, as established by EN 1998.1.1. (Eurocode 8) and Italian regulations. In this paper 48 buildings (33 with r.c. frames, 15 with masonry structure) have been selected on about 400 buildings erected between 1911 up to 1980, referred to a significant stock of social housings of the public company in the District of Leghorn (Italy). The PGA info of the soil have been easily found on the normative documentation. The structural performances of the several buildings have been synthetically investigated throughout two different procedures. The first one is the INGV $2^{\text {nd }}$ level form: it consist on the assessment of eleven parameters, based on specific instructions, able to furnish a dimensionless Vulnerability Index on a range 1-100. The second procedure consists of an equivalent static analysis of the structure, treated as a 3-dim frame, floor by floor, with the hypothesis of rigid slabs and beams. It furnishes an estimation of the peak ground acceleration capacity (PGAc) of the construction for Operation and Collapse limit values (SLO and SLC). In 
both cases the procedure is based on a geometrical survey and a visual inspection. Mechanical data on the structural performances of the frames (masonry / r.c.) can be obtained by literature info for masonry and non destructive tests for concrete.

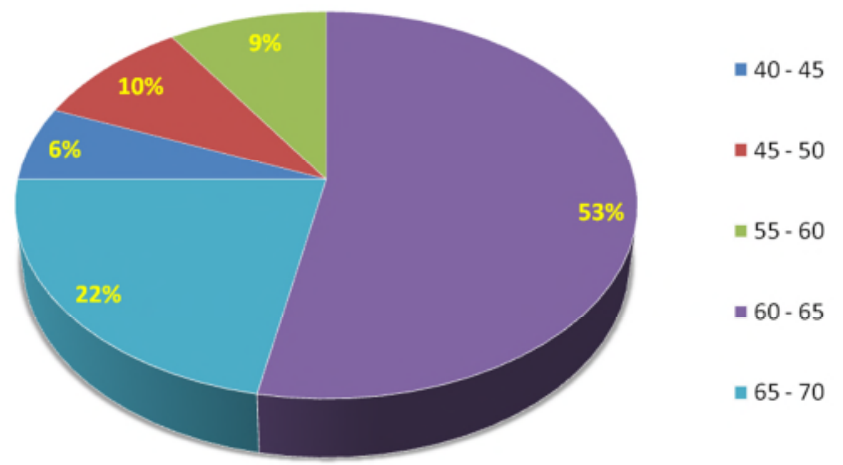

Fig. 1 Pie chart of Iv (masonry), or equivalent Iv (r.c. frames).
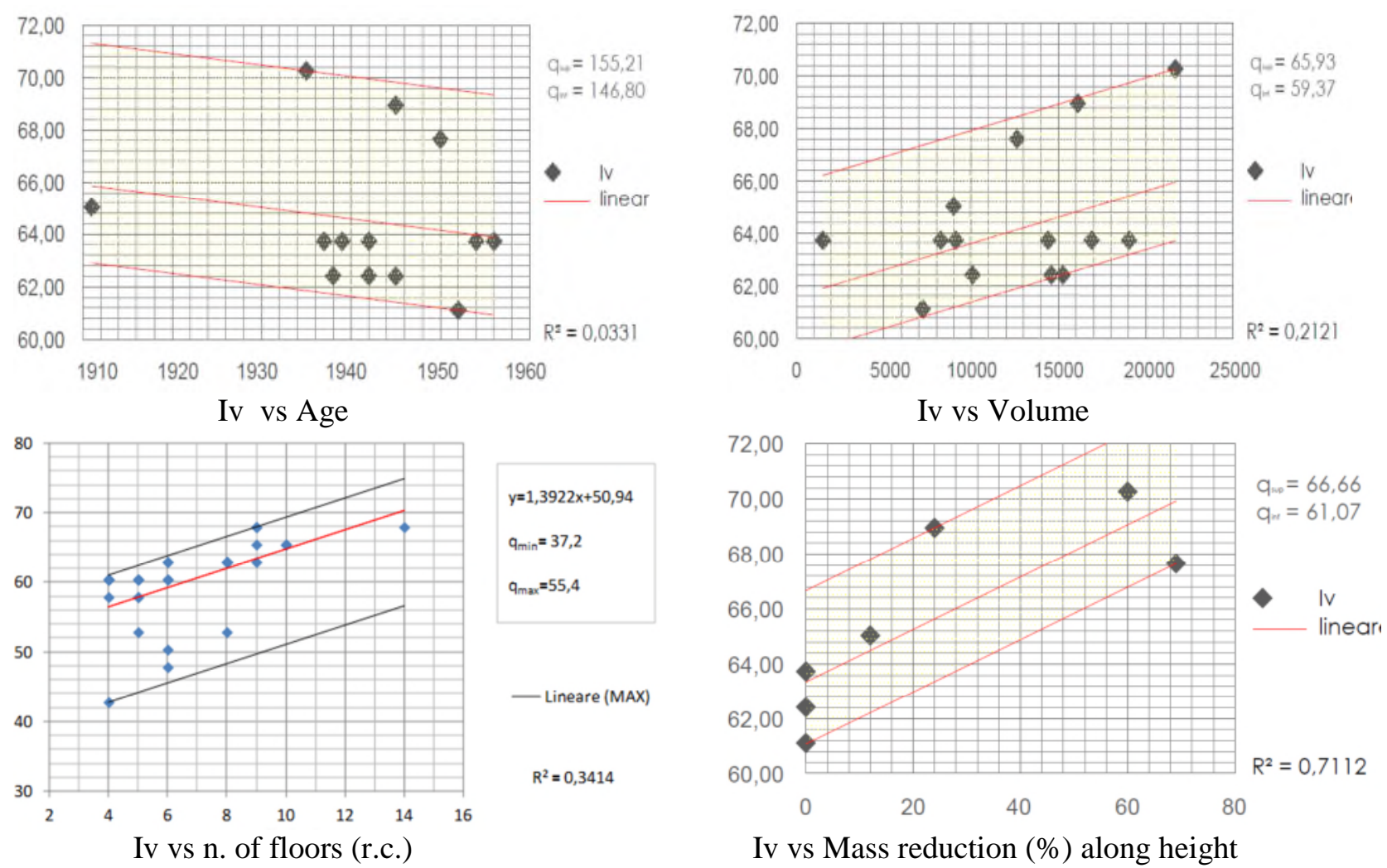

Fig. 2 Diagrams of Iv (Vulnerability Index).

\section{The INGV Procedure.}

This first procedure is limited to a quick assessment without any calculation method: it can only furnish overall scenarios without the capability of a correct evaluation of the seismic bearing performance. The results from the $2^{\text {nd }}$ level form for the considered stock of buildings are summarized in Fig. 1. The distribution of the results are comprised between a short range of Iv (Vulnerability Index) between 40 and 70. Although some indicators of seismic vulnerability are raised from this procedure, as in Fig. 2: the age of the building, the $\mathrm{n}$ of floors, the volume and the reduction of mass on height. The vulnerability is higher for enhancing volumes and number of floors of the buildings, with increasing irregularities along height and the construction age. It should observe that the method does not give correct values of the PGA demand, as verified by the authors 
in several technical reports for public entities. It should then confine its use only to assessment on priorities of interventions or investigations, postponing to appropriate calculation methods for more detailed seismic evaluations.

\section{The SAVE Procedure}

The info obtained by the simplified static analysis of SAVE are described in Fig. 3. The PGA capacities (PGAc) for masonry and r.c. housings of the stock are organized for increasing capacities, considering both collapse (SLC) or operation (SLO) levels. The results can be compared with the PGA demands of each location (PGAd), established by regulations, obtaining a first estimation of the index of seismic risk, as the ratio PGAc/PGAd. Some differences between SLO and SLC are detected, as in Fig. 4, where buildings with same SLC showed different SLO levels.
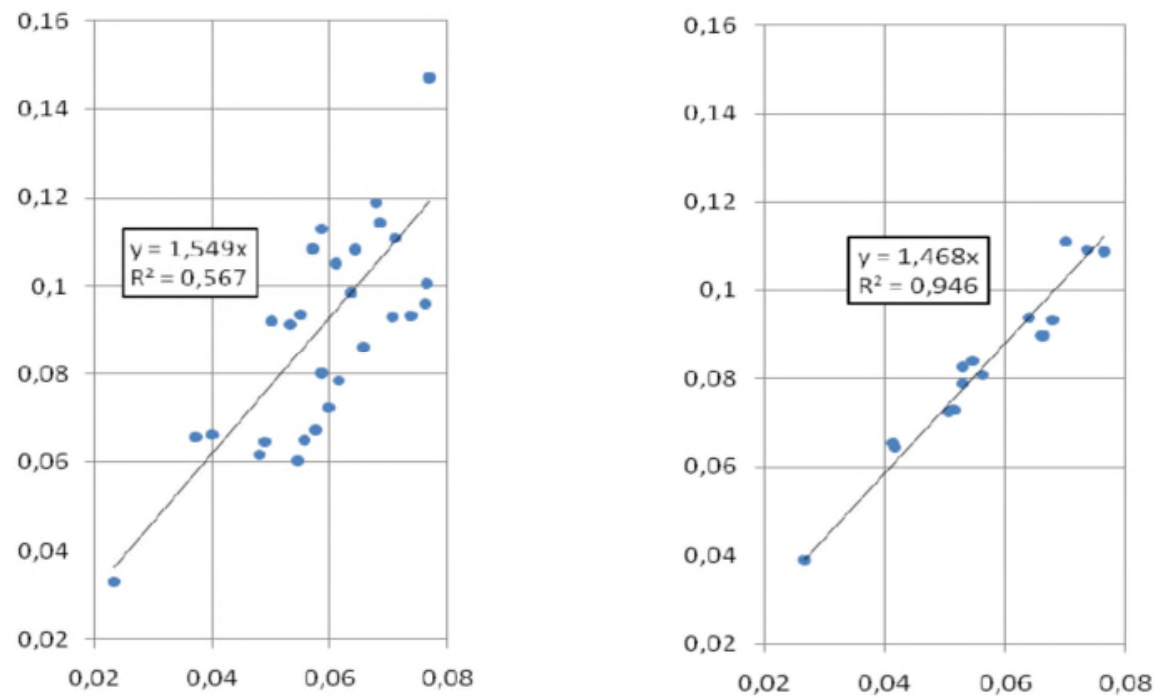

Fig. 3 ag $/ g$ (collapse) vs $a_{g} / g$ (operation) for R.C. buildings (left) and masonry buildings (right).

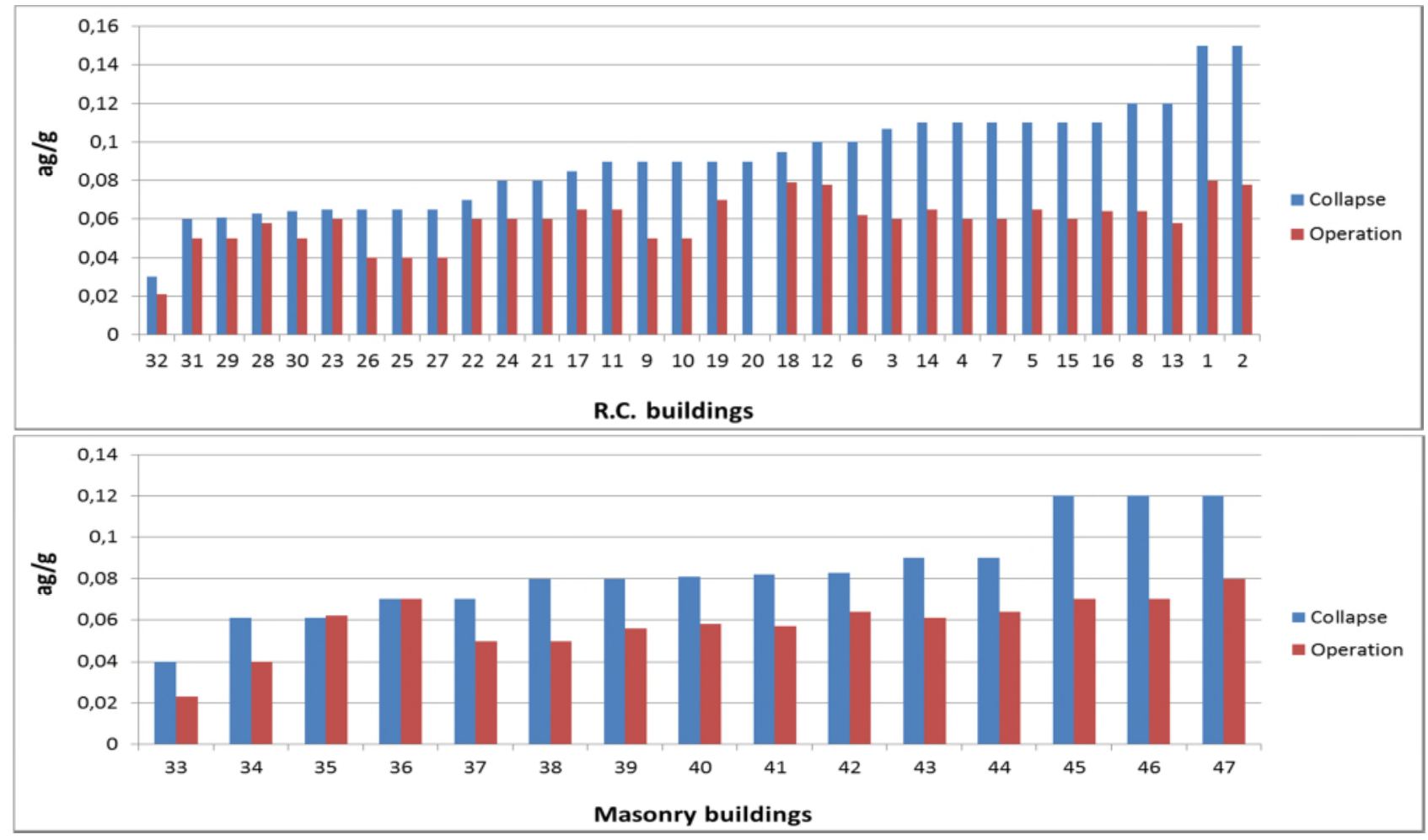

Fig. 4 PGA histograms from SAVE procedure. 


\section{Discussion}

Both procedures do not cover some relevant aspect of the seismic protection, related to structural and non structural elements. A first significant cause of seismic risk is given by rocking collapses of masonry walls or analogous vertical components (Fig. 5). The phenomenon is relevant from seismic point of view [2-4], but it could be activated also by extreme climatic scenarios [5, 6]. It can be reduced by temporary preventive steel rods [7] and evaluating the density of energy dissipated [8]. Another factor of risk are the inefficient constructive joints (Fig. 5). The negative effect of mutual impacts along the joints could be avoided by introducing specific dissipative elements, i.e. RCW [9] on vertical surfaces, moreover acting favorable biaxial states of stress [10]. Another negative aspect of the examined stock is the presence of non loadbearing cavity walls infilling r.c. frames.

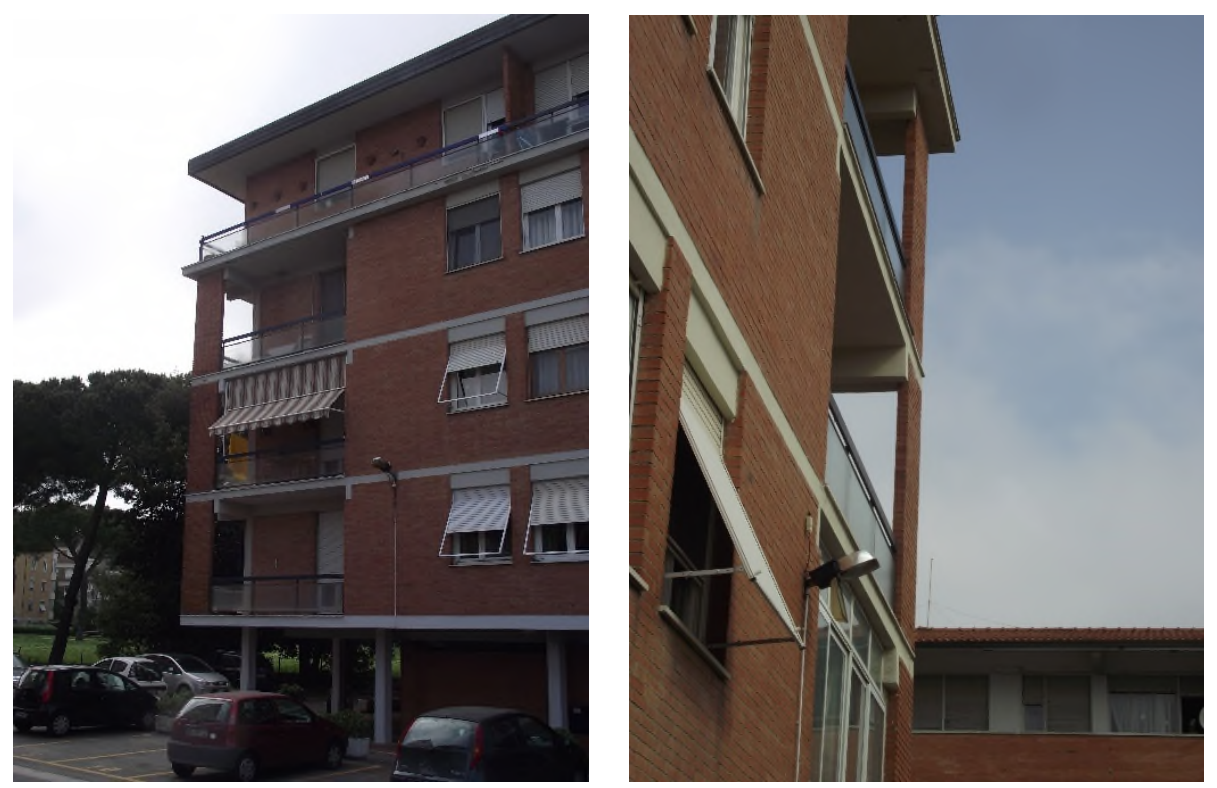

Figure 5. Example of vulnerable rocking walls.
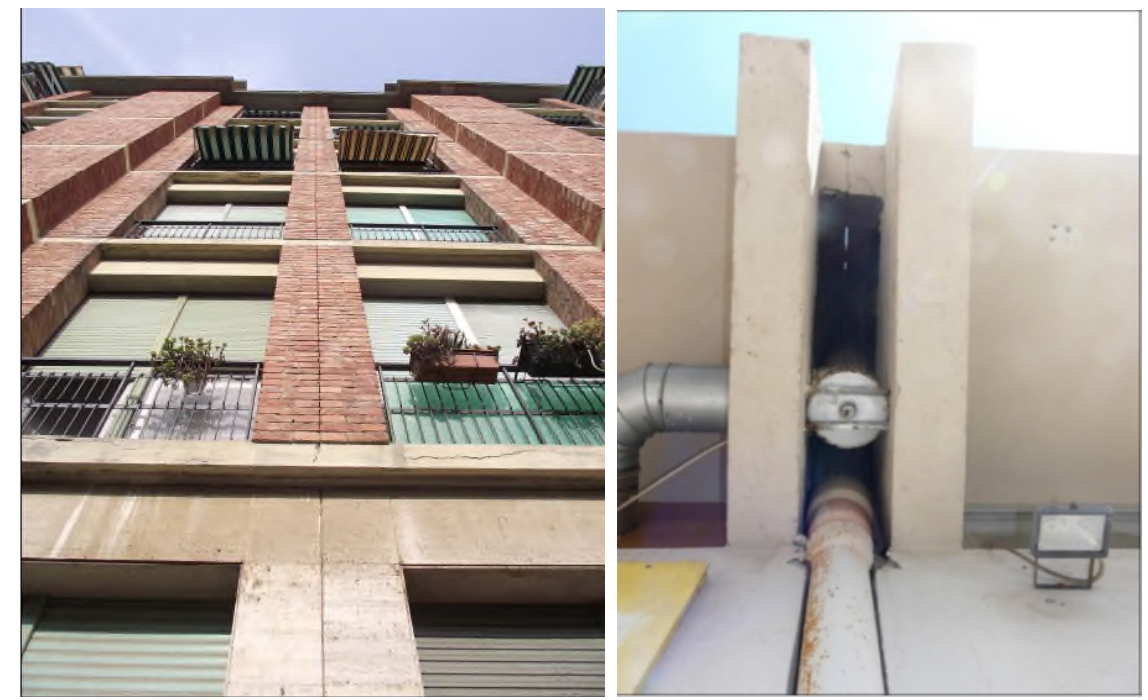

Fig. 6 Example of technical joints with inefficiency or improper use.

The replacement of the internal layers with lightweight and natural non loadbearing elements can join seismic protection with more sustainability, environmental friendly solutions and saving thermal energy [11]. The negative geometrical conditions of the ground level (Fig. 7), weakened by horizontal openings, hanging extremities of façades or undefended flexible columns are well known in literature and can be easily solved by external frameworks or shear walls [12-14]. 

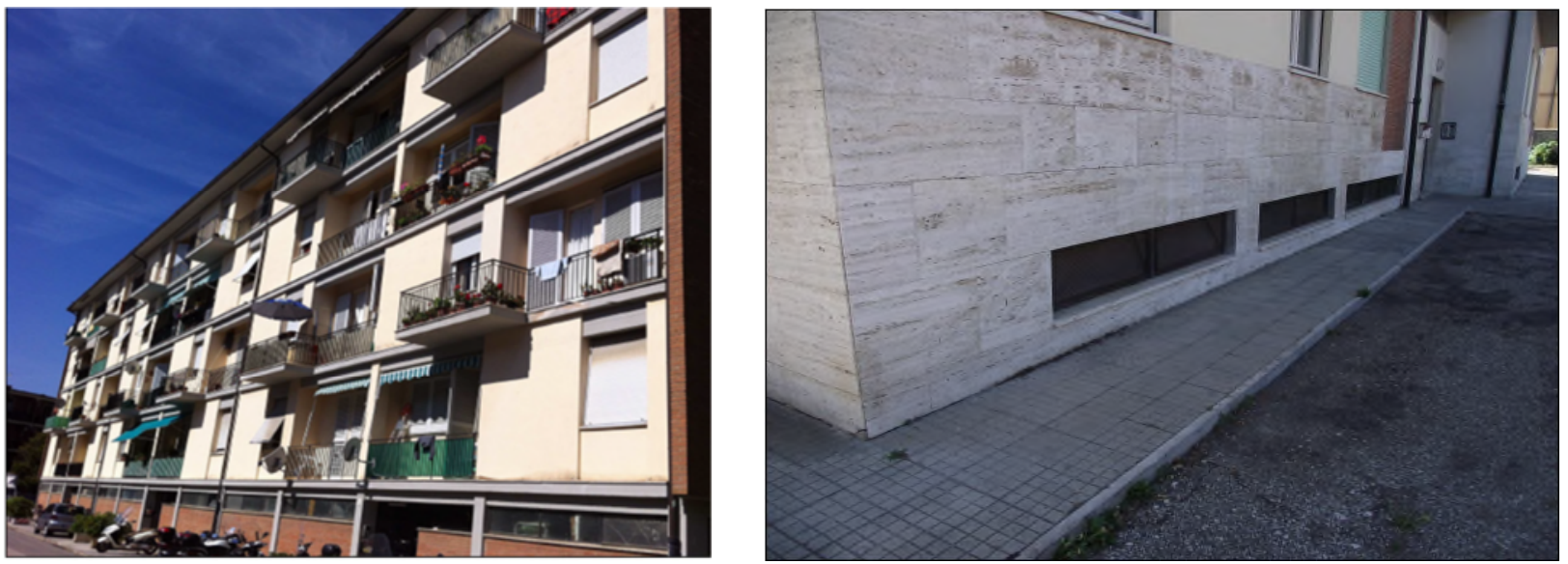

Fig. 7 Openings on the ground floor causing brittle collapse.
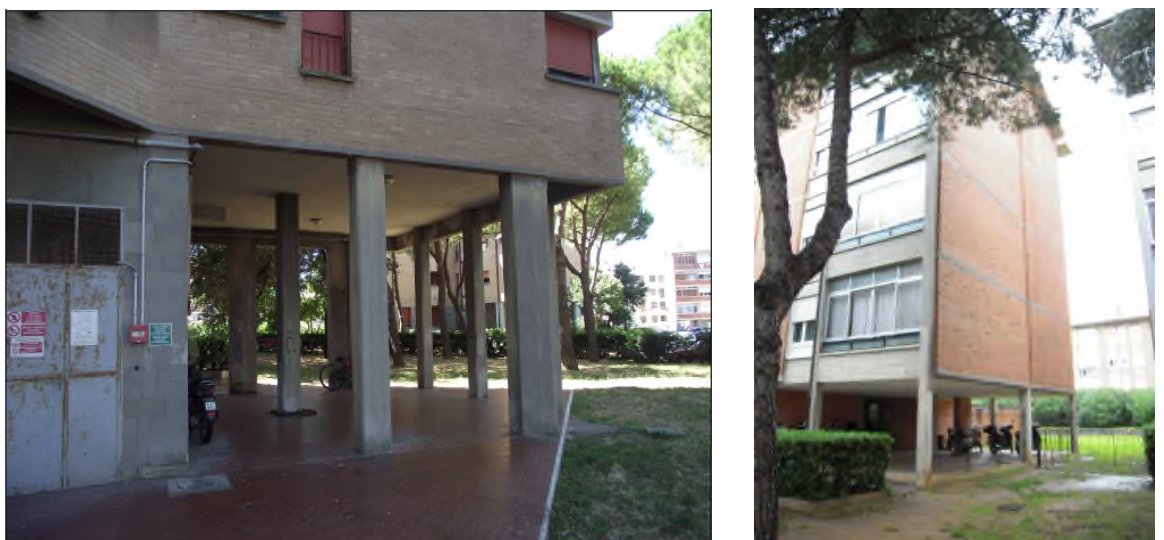

Fig. 8 Vulnerable extremities of façades and flexible ground floor.

\section{Conclusions and Perspectives}

Further aspect to raise are the needs of simple low destructive tests on r.c. frames and masonry walls, to enhance the knowledge of the structure of the stock. A useful procedure for monitoring r.c. elements is in $[15,16]$, while investigations on masonry walls with irregular texture can executed following the indications in $[17,18]$. A relevant aspect is also the role of the soil that can induce unexpected settlements as in [23]. All the above aspects can addressed to insurance contracts, in view to avoid litigations in case of defects raised after construction [19]. The insurance premium should take into account a Index of Risk, not only for seismic event but also as overall quality index. Periodic maintenance activities should considered and encouraged by way of reduction of the income itself. Finally the use of sustainable materials [20] joined with innovative processes can improve those buildings [21] including the analysis of fire risks [22].

\section{References}

[1] M. Andreini, A. De Falco, L. Giresini, M. Sassu. Structural damage in the cities of Reggiolo and Carpi after the earthquake on May 2012 in Emilia Romagna.Bull.Earth.Eng.(2014),12(5),24452480 .

[2] L. Rovero, V. Alecci, J. Mechelli, U. Tonietti, M. De Stefano, Masonry walls with irregular texture of L'Aquila: validation of a method for the evaluation of MQ. Mat. Str. (2016), 49, 22972314.

[3] L. Giresini, M. Fragiacomo, M. Sassu, Rocking analysis of masonry walls interacting with roofs. Engineering and Structures, (2016), 116, 107-120. 
[4] L. Giresini, M. Sassu, Horizontally restrained rocking blocks: evaluation of the role of boundary conditions with static and dynamic approaches, Bulletin of Earthquake Eng. (2017), 15, $385-410$.

[5] L. Giresini, M. Fragiacomo, P.B.Lourenço, Comparison between rocking analysis and kinematic analysis for the dynamic out-of-plane behavior of masonry walls. EESD (2015), 44(13), 2359-2376.

[6] M. Andreini, A. De Falco, L. Giresini, M. Sassu, Collapse of the historic city walls of Pistoia (Italy): causes and possible interventions. Appl. Mech. Mater. (2013), 352, 1389-1392.

[7] A. De Falco, L. Giresini, M. Sassu, Temporary preventive seismic reinforcements on historic churches: numerical modeling of San Frediano in Pisa. Appl. Mech. Mater. (2013), 352, 1393-1396.

[8] L. Giresini, Energy-based method for identifying vulnerable macro-elements in historic masonry churches, Bulletin of Earthquake Eng. (2016), 14(3), 919-942.

[9] M. Sassu, The Reinforced Cut Wall (RCW): A Low-Cost Base Dissipator for Masonry Buildings, Earthq. Spectr. (2006), 22, 533-554.

[10]M. Sassu, Biaxiality effect on the energy dissipated by elastoplastic base-isolators. J. Eng. Mech. (2003), 129, 607-612.

[11]M. Sassu, L. Giresini, E. Bonannini, M. L. Puppio, On the Use of Vibro-Compressed Units with Bio-Natural Aggregate, Buildings (2016), 6(3), 1-10.

[12] M. Andreini, A. De Falco, L. Giresini, M. Sassu, Seismic consolidation of '60s pilotis r.c. building for social housings with SCC-steel shear walls. Appl. Mech. Mater. (2014), 640, 19371942.

[13] A. De Falco, M. Froli, L. Giresini, M.L. Puppio, M. Sassu, A proposal for the consolidation of r.c. social housing by means of external hybrid steel-glass frameworks. Appl. Mech. Mat. (2014), 638, 3-8.

[14] L. Giresini, A. Gioeli, M. Sassu, Seismic reinforcement of a r.c. building with external steel frameworks: the case of the primary school XXV April of Arcola (Italy). Adv. Mater. Res. (2013), 834-836, 697-700.

[15]G. Vacca, F. Mistretta, F. Stochino, A. Dessi, Terrestrial laser scanner for monitoring the deformations and the damages of buildings, ISPRS Archives, (2016), 41, 453-460.

[16]F. Mistretta, M. V. Piras, M. L. Fadda, A reliable visual inspection method for the assessment of r.c. structures through fuzzy logic analysis, IALCCE 2014, (2015), pp. 1154-1160.

[17]M. Andreini, A. De Falco, L. Giresini, M. Sassu, Mechanical characterization of masonry walls with chaotic texture: procedures and results of in-situ tests. Int. J. Archit. Herit. (2014), 8, 1-32.

[18]L. Giresini, M. Sassu, Tests results and simple structural analysis of the main lighthouse in the Harbor of Livorno (Italy). Adv. Mater. Res. (2013), 834-836, 1299-1303.

[19] M. Sassu, A. De Falco, Legal disputes and building defects: some data from Tuscany (Italy). J. Perform. Constr. Facil. (2014), 28(4), 1-32.

[20] M. Sassu, L. Giresini, E. Bonannini, M. L. Puppio. On the Use of Vibro-Compressed Units with Bio-Natural Aggregate. Buildings, (2016), 6 (3), 40.

[21] M. Cipollini, E. Bonannini, M. Cinotti, M. Sassu, Design, Production, and Installation of Wooden Walls for the Japan Pavilion at Expo 2015. Buildings, (2016) 6 (1) 3-51. 
[22] M. Andreini, M. Caciolai, S. La Mendola, L. Mazziotti, M. Sassu, Mechanical behavior of masonry materials at high temperatures. Fire. Mater. 39(1) (2015) 41-57, ISSN: 0308-0501.

[23] M. Andreini, A. De Falco, L. Giresini, M. Sassu. Structural analysis and consolidation strategy of the historic Mediceo Aqueduct in Pisa (Italy). Appl. Mech. Materials, (2013), 351-352, 13541357 